\title{
El derecho administrativo disciplinario y su control judicial a la luz de la función pública ${ }^{1}$
}

\author{
Disciplinary administrative law and its judicial control \\ from a public function perspective
}

\author{
Sergio Luis Mondragón Duarte iD \\ Doctorando en Seguridad Humana y Derecho Global \\ Universidad Autónoma Latinoamericana-UNAULA, Medellín - Colombia. \\ Grupo de Investigación en Derecho Administrativo \\ Correo: sergio.mondragondu@unaula.edu.co
}

\section{Resumen}

El derecho disciplinario forma parte de la estructura pública inherente a toda organización estatal, independientemente de cual sea su naturaleza, con el fin de vigilar y controlar la conducta de los servidores públicos conforme a los principios rectores contenidos en su respectiva normatividad legal vigente, para permitir el cumplimiento de los fines e intereses del Estado. En ese sentido, dada la naturaleza autónoma e independiente de este derecho, vale la pena destacar los pilares que lo fundamentan, como son el ius puniendi del Estado, el principio de ilicitud sustancial y la relación de sujeción especial que existe entre ciertos agentes con el Estado.

Así mismo, al considerar que los fallos disciplinarios proferidos por órganos de control, como la Procuraduría General de la Nación, se adoptan en el marco del quebrantamiento o la perturbación de un deber funcional en el ejercicio de la actividad estatal por parte de servidores

1 Artículo de investigación científica derivado del proyecto de Tesis Doctoral titulado "La Judicialidad de la Actividad Administrativa Disciplinaria en el Ordenamiento Jurídico Colombiano", que fue aprobado por la Universidad Autónoma de Barcelona en el marco del plan de investigación de formación doctoral, el día 28 de septiembre de 2017. Así mismo, dicho proyecto fue registrado, avalado y financiado por la Universidad Autónoma Latinoamericana de Medellín en la Convocatoria CONVVI2019-01- Código 29-000002, bajo la modalidad de "Financiación proyectos de tesis doctorales o post-doctorales", con Acta de Inicio del 30 de abril de 2019. 
públicos o particulares que cumplen funciones públicas, es menester analizar el control pleno e integral de legalidad que efectúa la jurisdicción de lo contencioso administrativo a los mismos, dada la esencia que configura a estas decisiones como actos administrativos, para determinar si es necesario brindarles un tratamiento especial en el ordenamiento jurídico colombiano.

\section{Palabras clave:}

Derecho Disciplinario, Control Judicial, Función Pública, Actividad Administrativa, Acto Administrativo.

\section{Abstract}

Disciplinary law constitutes a part of the public structure inherent to every state organization, regardless of its nature, in order to monitor and control the conduct of public servants in accordance to the guiding principles contained in the respective current legislation, to allow the fulfillment of the purposes and interests of the State. In that sense, given the autonomous and independent nature of this right, it is worth pointing out the pillars that support it, such as the State's ius puniendi, the principle of substantial illicitly and the special subjection relationship that exists between certain agents with the State.

Likewise, considering that the disciplinary rulings issued by the control bodies, such as the Procuraduría General de la Nación (Attorney General's Office), are adopted within the framework of the breach or perturbation of a functional duty in the exercise of the state activity by public servants or particulars who perform public functions, it is due to examine the complete and integral control of legality that the jurisdiction for administrative proceedings applies to them, given the essence that configures these decisions as administrative acts, to determine if it is necessary to provide them with a special treatment in the Colombian legal system.

\section{Key Words}

Disciplinary law; judicial control; public function; administrative activity, administrative act.

\section{Cómo citar este artículo:}

Mondragón, S. L. (2020). El derecho administrativo disciplinario y su control judicial a la luz de la función pública. Revista de la Facultad de Derecho y Ciencias Políticas, 50 (132), pp. 100-122. doi: http://dx.doi.org/10.18566/rfdcp.v50n132.a05

Recibido: 15 de junio de 2019.

Aprobado: 27 de agosto de 2019. 


\section{Introducción}

La presente investigación da cuenta de la importancia que tiene el derecho administrativo disciplinario, como expresión de la potestad sancionatoria del Estado en el marco del ius puniendi. Es de especial relevancia el conocimiento de la actividad disciplinaria ejercida por parte de la Procuraduría General de la Nación y el control de sus decisiones por parte del Consejo de Estado.

Es por esto que, al referenciar los principios de la función pública como forma de garantizar el cumplimiento de los fines e intereses estatales, se halla inmersa la potestad disciplinaria como forma de control que tienen ciertas autoridades públicas para garantizar la igualdad, la moralidad, la eficacia, la economía, la celeridad, la imparcialidad y la publicidad dentro de todas las actuaciones desplegadas por los agentes del Estado. Se trata de servidores públicos o particulares, que sin serlo, tienen a cargo el ejercicio permanente o transitorio de la función pública o la administración de recursos públicos u oficiales. Es el caso de supervisores e interventores de contratos estatales (Ley 1474, 2011, art. 44).

Por consiguiente, es necesario evidenciar cómo el ejercicio de la función administrativa disciplinaria en Colombia tiende a garantizar el adecuado, correcto y eficiente desarrollo de la función pública. Sin embargo, también vale la pena establecer cómo en casos de expedición irregular de las decisiones disciplinarias, se promueve un control judicial frente a dichas decisiones por parte de la jurisdicción de lo contencioso administrativo, en aras de preservar la legalidad de los actos administrativos en el ordenamiento jurídico.

\section{Marco teórico}

Las teorías empleadas para desarrollar esta investigación se enmarcan en la teoría de las relaciones especiales de sujeción y la teoría de la norma subjetiva de determinación. La primera refleja el carácter especial que tienen los servidores públicos o particulares que ejercen funciones públicas con el Estado, por existir un "vínculo legal-reglamentario que surge entre el Estado y trabajador por virtud del acto de nombramiento y posesión” (Gómez Pavajeau, 2012, pág. 58) que demanda el compromiso de respeto y cumplimiento tanto de las normas como de las funciones La segunda teoría soporta el principio de ilicitud sustancial propio del derecho disciplinario "en la medida en que lo relevante para el Derecho Disciplinario, por estar profundamente influenciado 
por la ética, es la conducta y la dirección de la voluntad impuesta por los deberes” (Instituto de Estudios del Ministerio Público, 2007, p. 29).

De esta forma, se puede apreciar que el alcance dogmático de este estudio yace sobre la trascendencia y las formalidades que impregnan las categorías sobre las que se estructura el análisis del derecho disciplinario, en tanto para poder denotar la realización de los imperativos prescriptivos que contempla o consagra la función administrativa disciplinaria como expresión del ius puniendi del Estado para lograr sus fines, es necesario retomar las estructuras que lo fundamentan: los conceptos de ilicitud sustancial y relación de especial sujeción que existe entre los servidores públicos o particulares que cumplen funciones públicas con el Estado.

\section{Metodología}

El enfoque de esta investigación es cualitativo, toda vez que se pretende dar a conocer la relevancia del derecho administrativo disciplinario en la función pública y su control de legalidad ante la jurisdicción de lo contencioso administrativo. Por consiguiente, esta requiere de la extracción de significados, conceptos y posiciones a partir de los datos recolectados y se justifica en el análisis de las múltiples realidades subjetivas que comporta el estudio de las categorías de la investigación (Hernández, 2014) desde la información teórica que llegase a ser recopilada en torno a la esencia de la función pública, la naturaleza del derecho disciplinario y el control judicial a los fallos disciplinarios.

Así mismo, el método para el estudio de cada una de las categorías de esta investigación es el hermenéutico, esto es, una actividad interpretativa de textos en diferentes contextos (Arráez, Calles, \& Moreno de Tovar, 2006), en este caso concreto obedece al análisis del derecho administrativo disciplinario en el marco de la función pública y su control de legalidad ante la jurisdicción de lo contencioso administrativo. De este modo, la interpretación de las categorías de función pública, derecho disciplinario y control judicial a fallos disciplinarios se comprenden en un marco de relación e integración, propia del análisis, la sistematización y la comparación que permite este método hermenéutico.

Finalmente, las fases del desarrollo de esta investigación son: la de recolección de información, análisis de los datos y presentación de los resultados. Estas fases se basan en la revisión de la literatura que se hace 
de las fuentes de información, tales como artículos indexados, libros físicos y electrónicos, bases de datos y páginas web confiables (Hernández, 2014), a través de las cuales se logra consolidar una interpretación integral y sistemática de la documentación.

\section{La función pública en el marco de la actividad administrativa disciplinaria}

La función pública, entendida como el conjunto de actividades promovidas por las entidades públicas dirigidas a satisfacer los intereses de la población, ha evolucionado como una estructura organizacional desarrollada por funcionarios o empleados estatales para garantizar el cumplimiento de servicios públicos (Basconcelos, 2005), a un medio que le permite a los particulares, incluso a los mismos servidores públicos, entablar una relación de confianza con las entidades estatales. De tal manera que pueda encontrar en ellas un respaldo o aval para acceder al goce pleno de sus intereses individuales enmarcados en Derechos subjetivos (Gordillo, 2012), exigibles, mediante el ejercicio de acciones públicas que dan lugar al inicio de actuaciones administrativas o judiciales.

En este sentido, vale la pena destacar la necesidad de asegurar el óptimo funcionamiento de las instituciones públicas con sujeción a los postulados normativos contenidos dentro del ordenamiento jurídico (Centro Latinoamericano de Administración para el Desarrollo CLAD, 2013). Esto mediante el uso apropiado de las potestades disciplinarias con que cuentan las diferentes organizaciones estatales, para la ejecución oportuna, efectiva y eficiente de las actividades públicas.

De esta manera, nace el derecho disciplinario como parte integral de la estructura pública inherente a toda organización estatal, independientemente de cual sea su naturaleza, con el fin de vigilar y controlar la conducta de los servidores públicos, conforme a los principios rectores contenidos en su respectiva normatividad legal vigente, para permitir el cumplimiento de los fines e intereses del Estado.

Por consiguiente, se puede avizorar que la finalidad del derecho disciplinario, situado dentro del contexto de la función pública propiamente dicha, consagra dos propósitos: uno externo y otro interno. A nivel externo, la utilidad primordial de la actividad sancionadora, que consiste en una configuración reguladora de 
conducta de los servidores públicos, se dirige a la obtención de una correcta prestación del servicio público con relación a los individuos particulares que, conforme a la relación de sujeción especial que tienen con el Estado, pueden trabar una relación jurídica originada en la activación de aparatos administrativos o jurisdiccionales. Y a nivel interno, dicha vertiente se ubica en el marco de la lealtad, la responsabilidad y el respeto que le deben los mismos funcionarios, empleados, trabajadores oficiales, asesores y contratistas a las instituciones públicas para las que prestan sus servicios e, igualmente, hacia aquellas respecto de las que no se genera un vínculo laboral directo, en virtud del principio de colaboración previsto al interior de la Constitución Política de 1991 (Boletín Oficial del Día, 2014).

Es así como el desconocimiento o incumplimiento normativo en el ejercicio de actividades públicas específicas, por ejemplo las contractuales, es objeto de reproche dentro del proceso disciplinario, por cuanto genera una perturbación lesiva o un quebrantamiento funcional de los fines del Estado consagrados en el artículo 209 del texto constitucional (Constitución Política, 1991, art. 209), que traducen concretamente en la moralidad, la transparencia pública, el respeto por la dignidad humana, el debido proceso, la efectiva y eficiente prestación del servicio público (López Pedraza \& Yara Delgado, 2011).

Por tanto, el interés del derecho disciplinario frente a la función pública se promueve con relación a la licitud de la conducta del servidor público, pues su espectro de aplicación opera a partir del momento en que se incumple un deber funcional, materializado en una ilicitud proveniente de la vulneración del régimen de inhabilidades, incompatibilidades, deberes, prohibiciones y conflictos de intereses por acción, omisión o extralimitación en la realización de sus labores. De esto deviene la imposición de la sanción disciplinaria, como forma de "reprimir las acciones u omisiones previstas en las infracciones" (Ramírez \& Aníbal, 2015, p. 113) catalogadas como faltas disciplinarias, cuya finalidad principal como se dijo previamente es: "salvaguardar la obediencia, la disciplina, la rectitud y la eficiencia de los servidores públicos” (Sentencia C-818, 2005).

De esta forma, el derecho disciplinario se emplea en la actualidad como un instrumento encaminado a enderezar las conductas desplegadas por los servidores públicos en el ejercicio de sus actividades, que le permite cumplir con las reglas de sujeción impuestas por el ordenamiento jurídico adoptado por el Estado. Esto justifica el ejercicio de dicha potestad sancionatoria desde "la inspección jerárquica, la sanción normalizadora y su combinación en un procedimiento que le es específico: examen” (Márquez, 2010, p. 121). 
Es por esto que desde la esfera de la función pública, la fundamentación del derecho disciplinario comporta: "un instrumento clave en la lucha contra la impunidad, la ineficacia y la corrupción administrativa, flagelos que representan la antítesis del derecho colectivo a la moralidad administrativa, y una barrera infranqueable para lograr materializar el principio de igualdad" (Forero, 2016, p. 23).

\section{La naturaleza del derecho disciplinario en Colombia}

El derecho disciplinario constituye una parte del derecho administrativo sancionador, y se concibe como aquella potestad que tiene el Estado para sancionar a sus propias autoridades o agentes en el marco de la función pública. En ese sentido, la Corte Constitucional en Sentencia C-341 de 1996 (Sentencia C-341 de 1996) señala que el derecho disciplinario:

Comprende el conjunto de normas, sustanciales y procesales, en virtud de las cuales el Estado asegura la obediencia, la disciplina y el comportamiento ético, la moralidad y la eficiencia de los servidores públicos, con miras a asegurar el buen funcionamiento de los diferentes servicios a su cargo (Sentencia C-341 de 1996).

Con base en esta definición que trae la jurisprudencia constitucional en materia de derecho disciplinario se encuentra que el propósito de esta área del derecho es conducir las actuaciones de los servidores públicos o particulares, que tienen a cargo el cumplimiento de funciones públicas, en el marco de la legalidad, rectitud, transparencia, eficacia, eficiencia y moralidad estatal.

En ese sentido, Gómez Pavajeau (2011) ha precisado que el derecho disciplinario en Colombia se ha erigido como una "ciencia autónoma e independiente" (pág. 125). De esta manera, es necesario destacar que lo que se conoce como dogmática del derecho disciplinario nace del conjunto de estructuras propias que integran esta área del derecho (teorías sobre el ius puniendi del Estado, la ilicitud sustancial y las relaciones especiales de sujeción), que lo diferencian tanto del derecho penal como del derecho administrativo en su esencia.

En consecuencia, se tiene que el ejercicio de la potestad disciplinaria encuentra su fundamento en el ius puniendi del Estado (Sentencia C-818, 2005), dado que cuando se despliegan conductas que son contrarias a la ley, el 
Estado mismo debe encargarse a través de entidades, órganos y autoridades, investigar y sancionar a las personas que incurrieron en dichas faltas ${ }^{2}$. Por tanto, a partir del concepto del ius puniendi del Estado se concibe el derecho disciplinario como:

El ejercicio del derecho del Estado a sancionar (ius puniendi) las faltas disciplinarias que cometan sus servidores para prevenir conductas contrarias al cumplimiento recto del servicio público y leal de la función pública, lesivas de los bienes jurídicos protegidos con ellas, debe estar revestido de todas las garantías de orden sustantivo y procesal, consagradas constitucional y legalmente para los regímenes sancionatorios. (Sentencia C- 948 de 2002)

Respecto de la ilicitud sustancial, se puede decir que este es el punto fuerte o clave que demanda o reclama la autonomía del derecho disciplinario, por cuanto el artículo 9 del nuevo Código General Disciplinario señala que: "la conducta del sujeto disciplinable será ilícita cuando afecte sustancialmente el deber funcional sin justificación alguna, habrá afectación sustancial del deber cuando se contraríen los principios de la función pública” (Ley 1952, 2019, art. 9) . Esto junto a las nuevas teorías que se plantean de la ilicitud sustancial permiten entrever que:

La "ilicitud sustancial" en el Derecho disciplinario, es el aditamento que le da sustento a la consumación de la falta, pues se podría decir que con la conducta desplegada por el Servidor Público efectivamente se viola el ordenamiento jurídico disciplinario, pues esta falta al deber como agente del Estado, mientras que, en el Derecho penal, el injusto penal es porque se vulnera o se pone en peligro el bien jurídicamente tutelado por el Estado (Ardila Quiroz et al. 2010, p. 58).

Respecto de lo anterior, vale la pena aseverar que el Consejo de Estado en Colombia ha manifestado que el concepto de ilicitud sustancial hace alusión no

2 La potestad sancionatoria con que cuenta el Estado para sancionar a sus servidores públicos o agentes estatales, otorga autonomía e independencia al derecho disciplinario y se distingue de otras ramas del derecho como la penal o el administrativo, por cuanto la finalidad última de esta categoría de derecho sancionador es reprochar la conducta de un servidor público o particular que, habiendo cumplido funciones a nombre del Estado, incurre en una falta considerada de forma preexistente, como disciplinaria, en el marco de un derecho, un deber, una omisión o prohibición, una inhabilidad, una incompatibilidad o un conflicto de interés. Lo que retira inmediatamente el carácter condenatorio, contravencional o administrativo con que cuentan las otras dos áreas del derecho. 
a cualquier comportamiento contrario a la ley, como ocurre en materia penal; sino que dicha conducta debe repercutir de forma relevante en el cumplimiento de los fines estatales:

La referencia a sustancial en relación con la ilicitud, significa que la infracción del deber sustancial debe tener cierta relevancia, importancia o esencial frente a los fines del Estado, la satisfacción del bien general y los principios de la función pública. En términos generales, esto quiere decir, que la actuación u omisión del servidor público violatoria de sus deberes, es decir, contraria a derecho (ilicitud), debe desembocar en una real y efectiva afectación del buen funcionamiento del Estado y por tanto del servicio público (sustancialidad) y en esa medida puede decirse, pese a que la ley no lo mencionó de este modo, que cuando estas dos características confluyen se está en presencia de una (antijuridicidad sustancial», requisito indispensable para que pueda afirmarse que se configuró una conducta disciplinaria susceptible de ser sancionada (Sentencia 2013-01092-00, 2018).

De esta manera queda claro que, si bien el concepto de antijuridicidad formal se comparte tanto desde el punto de vista del derecho penal como del derecho disciplinario, la concepción de antijuridicidad material varía de forma considerable con relación a ambas áreas del derecho. Dado que, si bien en materia penal se requiere solo que el denunciado o presunto autor del delito penal despliegue una conducta contraria a derecho que transgreda un bien jurídico tutelado por el Estado; para que esta se configure o catalogue como antijurídica; en materia disciplinaria, el investigado o presunto infractor de un deber, un derecho, una omisión o prohibición, una extralimitación, una inhabilidad, una incompatibilidad, o un conflicto de interés debe haber incurrido en una falta que genere una afectación real o perturbación funcional a los intereses o fines estatales.

Ahora bien, dentro del estudio de la estructura dogmática del derecho disciplinario, se destaca el concepto de relación de especial sujeción, como aquella categoría específica de relación que existe entre el Estado, a través de sus entidades, con los servidores públicos o particulares que ejercen funciones públicas. Esto se distingue claramente de la relación que existe entre aquel con los particulares, dado que el comportamiento de estos últimos solo puede ser reprochable por violación de la constitución y la ley; en tanto que el de los primeros, además de poder ser sancionados por las mismas causales de los particulares, también pueden serlo por acción, omisión o extralimitación en el 
ejercicio de sus funciones. Es de esta manera que atendiendo al contenido de varios autores en derecho disciplinario:

Las relaciones especiales de sujeción son propias de los Estados donde el gobierno no es el Estado, ni está por encima de él, existen precisamente para que quienes están sujetos al Estado lo hagan bien, y, permitan el progreso del mismo, y por ende, de quienes lo habitan, por eso es que encontrándose en unas relaciones especiales de sujeción, se debe dar parte de todos los movimientos que haga el funcionario a cargo del Estado, la relación especial de sujeción debe servir para investigarlo y sancionarlo, si hay oportunidad a ello, por eso hacen parte del Derecho disciplinario.(Ardila Quiroz et al. 2010, p.47)

Esta situación presentada en un contexto más amplio, se ratifica por otros doctrinantes del derecho disciplinario, quienes presentan un panorama mucho más holístico y sistemático del tema, cuando se refieren al concepto de relación especial de sujeción en el marco de la potestad disciplinaria del Estado, como categoría dogmática superior de orden constitucional:

En la propensión de concebir el derecho disciplinario como una ciencia del ordenamiento jurídico colombiano autónomo e independiente, con sus propias especificidades y cualidades, la "Relación Especial de Sujeción", como categoría dogmática de origen y desarrollo constitucional, se erige como bastión de esa calificación [...] Como categoría, impone entenderla básicamente como una cualidad que se atribuye al derecho disciplinario; dogmática, en la medida en que su justificación, su sentido y su alcance se ha desentrañado con base en el método de interpretación de la norma jurídica conocido como “Dogmático”, lo que sin duda le otorga una valoración construida sobre criterios objetivos de racionalidad; superior de orden Constitucional porque es precisamente allí en la jurisdicción de la Corte Constitucional, y en la tarea de guardar la integridad y supremacía de la Constitución en donde se ha venido dando su génesis y su desarrollo, sobre los mencionados criterios objetivos de racionalidad. (Instituto de Estudios del Ministerio público, 2007, p. 25)

Así mismo, a la luz de la jurisprudencia constitucional, se tiene que la relación de sujeción especial que existe entre los servidores públicos y el Estado fundamenta la potestad disciplinaria en la medida que: 
Constituye un elemento fundamental del Estado de Derecho, el deber de los servidores públicos de cumplir sus obligaciones de conformidad con lo establecido en las normas vigentes. El reconocimiento de ese deber y la responsabilidad consecuente en caso de incumplirlo, se encuentra previsto específicamente en el artículo $6^{\circ}$ de la Carta conforme al cual los servidores públicos son responsables por infringir la Constitución y las leyes, de una parte y por la omisión o extralimitación en el ejercicio de las funciones asignadas. En plena consonancia con ello, el artículo 122 de la Carta prevé que todos los servidores públicos, antes de entrar a ejercer su cargo, deberán prestar juramento de cumplir y defender la Constitución, así como desempeñar los deberes que les incumben. Adicionalmente el artículo 123 prescribe que los servidores públicos ejercerán sus funciones en la forma en que ello se encuentre previsto por la Constitución, la ley y el reglamento. Este punto de partida, que cualifica la condición del servidor público y determina su relación de sujeción, se encuentra signado además por la regla según la cual la función pública debe encontrarse al servicio de los intereses generales y, en esa medida, las autoridades públicas deben respetar los principios de igualdad, moralidad, eficacia, economía, celeridad, imparcialidad y publicidad. (Sentencia C-500, 2014).

Esto justifica, como bien lo ha señalado la Corte Constitucional, que el Estado le imponga a los servidores públicos o particulares que cumplan funciones públicas "cargas y obligaciones adicionales a las de cualquier ciudadano, en la medida en que es su responsabilidad la consecución de los propósitos estatales” (Sentencia C-252, 2003). Es por esta razón que, en cumplimiento de un deber funcional es que los agentes estatales pueden responder disciplinariamente, dado que el mismo Consejo de Estado también ha incorporado esta característica como pilar que fundamenta la relación de especial sujeción entre el Estado con sus administrados a partir del derecho disciplinario:

El (deber funcional» que contempla el artículo 5 de la Ley 734 de 2002, se desprende de la relación especial de sujeción existente entre el Estado y los servidores públicos. Específicamente, hace referencia a la obligación que le asiste a estos de: i) Cumplir el conjunto de funciones asignadas a su cargo, ii) actuar conforme la Constitución Política, la ley o el reglamento, y, iii) garantizar el adecuado funcionamiento del Estado, la prevalencia del interés general y de los fines del Estado. En efecto, el deber funcional es catalogado como el medio a través del cual se cumplen los fines estatales (Sentencia 2013-01092-00, 2018). 
De conformidad con lo esbozado previamente se puede decir que la importancia del estudio del derecho disciplinario yace en el conocimiento que deben tener tanto los servidores públicos como los particulares que ejercen funciones públicas acerca del régimen de derechos, deberes, prohibiciones, inhabilidades, incompatibilidades o conflictos de interés que los cobija; en virtud de lo cual podrían verse incursos en investigaciones y, a su vez, inmersos en sanciones por las presuntas faltas o infracciones que cometan con ocasión de dicho régimen.

\section{Control de legalidad de actos administrativos disciplinarios}

La Ley 734 del 05 de febrero de 2002 (Ley 734, 2002), actual Ley 1952 del 28 de enero de 2019 (Ley 1952, 2019), en desarrollo de lo previsto por el numeral 6 del artículo 277 de la Constitución Política de 1991 (Constitución Política de Colombia, 1991, art. 277), dispuso en su artículo segundo (Constitución Política de Colombia, 1991, art. 2), que el poder preferente para adelantar investigaciones disciplinarias se encuentra radicado en la Procuraduría General de la Nación, sin perjuicio de la facultad con la que cuentan otras entidades para ejercerla directamente. Sin embargo, en uno u otro caso, las decisiones proferidas por estas entidades pueden ser objeto de control judicial por parte de la Jurisdicción Contencioso Administrativa, a través del medio de control de nulidad y restablecimiento del derecho, regulado por el artículo 138 del Código de Procedimiento Administrativo y de lo Contencioso Administrativo (Ley 1437, 2011, art. 138).

Este control de legalidad se lleva a cabo al invocar en las demandas de nulidad y restablecimiento del derecho las causales consagradas en el artículo 137 de la Ley 1437 de 2011 (Ley 1437, 2011, art. 137), tales como la expedición del acto administrativo con: "infracción de las normas en que deberían fundarse, o sin competencia, o en forma irregular, o con desconocimiento del derecho de audiencia y defensa, o mediante falsa motivación, o con desviación de las atribuciones propias de quien los profirió" (Ley 1437, 2011, art. 137).

De forma primigenia, la posición jurisprudencial sentada al respecto por el Consejo de Estado (1997) indicaba que la revisión realizada a dichos actos administrativos en sede judicial era de legalidad; mas no de corrección o de cuestionamiento probatorio. De este modo, no se permitía retrotraer 
las actuaciones del proceso disciplinario en el proceso judicial para atacar cuestiones debatidas en la instancia administrativa ya agotada, pues proceder de forma contraria implicaría reabrir el expediente procesal para debatir asuntos que ya habían sido resueltos de fondo al interior del proceso disciplinario.

En ese sentido, la jurisprudencia del Consejo de Estado (Sentencia 2004-05678-02, 2010) había indicado que el control judicial promovido con relación a los actos administrativos sancionadores contaba con limitaciones y restricciones, que le impedían convertirse en una tercera instancia. Es así como en Sentencia del 03 de septiembre de 2009 esta Corporación expresó: "De esta manera la posibilidad de demandar ante la Jurisdicción Contenciosa Administrativa las providencias que culminan el proceso disciplinario, no implica trasladar, de cualquier manera, a la sede contenciosa administrativa el mismo debate agotado ante las autoridades disciplinarias" (Sentencia 200500113-00, 2009). Esta situación permitía entrever que, a través del medio de control de nulidad y restablecimiento del derecho impetrado ante la jurisdicción de lo contencioso administrativo, solo se podía realizar un debate de forma en el momento de controvertir la decisión que profirió el órgano de control; mas no de fondo.

Por tanto, el estudio emanado del contenido del acto administrativo sancionador quedaba desprovisto de cualquier análisis de fondo sobre la exclusión del debate probatorio. Salvo que por transgresión al debido proceso disciplinario se atentara contra el ejercicio del derecho de contradicción y/o defensa, pues el mismo no podía convertirse en una tercera instancia que reabriera el debate probatorio desde su apreciación o controversia (Sentencia 2004-05678-02, 2010).

En ese sentido para dicho órgano judicial la posibilidad que tenía la misma jurisdicción de lo contencioso administrativo de entrar a efectuar un estudio de fondo a las decisiones proferidas por los órganos disciplinarios, en especial a las expedidas por la Procuraduría General de la Nación o sus entidades delegadas, quedaba relegada a un simple abordaje de forma. Toda vez que el ejercicio de la potestad disciplinaria en sí misma sólo le había sido confiada estrictamente a tales órganos de control; pero no a la autoridad judicial; esto en apoyo de la misma doctrina soportaba la tesis de no revivir el debate probatorio agotado en la instancia del proceso administrativo disciplinario, dentro del proceso judicial, por no tratarse este último de una tercera instancia (Gómez Pavajeau \& Sánchez Herrera, 2009). 
Así, el Consejo de Estado en reiteradas oportunidades señaló que el control judicial adelantado por la Procuraduría General de la Nación no podía corresponder a una tercera instancia que revisara aspectos de fondo relacionados con la controversia ya resuelta en sede administrativa; sino a un poder correccional (Sentencia 2008-00072-00, 2011) orientado a esclarecer hechos transgresores de "los valores constitucionales más preciados, como el debido proceso, el derecho defensa, la competencia del funcionario y de modo singular, si la producción y la valoración de las pruebas se hizo atendiendo estrictamente las reglas señaladas en la Constitución y en la ley" (Sentencia 2004-05678-02, 2010). Este tiene su origen en las causales de nulidad de los actos administrativos, propuestas por el sancionado en la demanda contenciosa administrativa para obtener la revocatoria del fallo disciplinario a través de este instrumento judicial.

Sin embargo, en torno a este tema, el Consejo de Estado varió su posición jurisprudencial claramente a comienzos del año 2013, cuando en distintas decisiones judiciales sostuvo que la jurisdicción de lo contencioso administrativo podía llevar a cabo control pleno e integral a los fallos disciplinarios proferidos por la Procuraduría General de la Nación o sus entidades delegadas. Dado el simple alcance administrativo que revisten las decisiones adoptadas por estos órganos (Sentencia 2011-00115-00, 2013).

En consecuencia, este Alto Tribunal en Sentencias - como la proferida el día 11 de julio del 2013 (Sentencia 2011-00122-00, 2013) con Ponencia del Doctor Gustavo Eduardo Gómez Aranguren- sostuvo que la Jurisdicción Contencioso Administrativo carecía de límites para realizar un control, tanto formal como material, a los actos administrativos expedidos por los órganos disciplinarios. Debido a que la misma Ley 1437 de 2011 (Ley 1437, 2011) la reconoce como la autoridad que tiene a cargo la potestad jurisdiccional para determinar la legalidad o ilegalidad de cualquier tipo de acto administrativo en el ordenamiento jurídico colombiano, incluidos los de naturaleza disciplinaria (Sentencia 2011-00122-00, 2013).

Así mismo, esta posición fue reiterada en Sentencia del 21 de noviembre de 2013, en la que se indicó que la jurisdicción de lo contencioso administrativo no tiene límites para abordar el estudio de fondo de los fallos disciplinarios emanados por la Procuraduría General de la Nación, pues sus decisiones no ostentan el carácter de judicial. Lo que sí ocurre con aquellas decisiones emanadas al respecto por la Sala Disciplinaria del Consejo Superior de la Judicatura o sus seccionales (Sentencia 2011-00190, 2013). 
Esta postura tomó fuerza también en el Consejo de Estado a partir de la decisión adoptada por la Corte Constitucional en la que declaró la exequibilidad de los artículos 47, 48 y 49 de la Ley 1474 de 2011 (Ley 1474, 2011, arts. 47, 48, 49). Mediante estos avaló la revocatoria de los autos de archivo y los fallos absolutorios producidos dentro del proceso disciplinario, dada la naturaleza administrativa de tales actos (Sentencia C-306, 2012). Luego adquirió mucho más vigor a partir de ciertas decisiones judiciales que definieron la situación de permanencia en el cargo de funcionarios públicos de elección popular, como fue el caso de la sanción de destitución e inhabilidad general impuesta en su momento por la Procuraduría General de la Nación a Piedad Esneda Córdoba Ruiz, en la que el Alto Tribunal de lo Contencioso Administrativo expuso que la naturaleza de las decisiones disciplinarias proferidas por la Procuraduría General de la Nación son de carácter administrativo. Es por esto que la autonomía, independencia e imparcialidad solo puede reconocerse a las decisiones de autoridades que tienen a cargo función jurisdiccional, pues "los actos proferidos en virtud de ella no tienen ningún tipo de control exógeno a la misma función judicial” (Sentencia 2011-00316-00, 2016), luego, "no es comparable, ni de lejos, el titular de la acción disciplinaria de naturaleza administrativa con el rango y la investidura de un juez de la República” (Sentencia 2011-00316-00, 2016); ya que "aceptar tal tesis, es revivir la deferencia especial o la intangibilidad relativa de las decisiones adoptadas por la administración” (Sentencia 2011-00316-00, 2016) ${ }^{3}$.

Esta situación toca fondo, en la medida que el Consejo de Estado no reconoce a la Procuraduría General de la Nación como juez natural de los procesos disciplinarios. A la luz de sus decisiones amparadas igualmente en decisiones internacionales como las de la Corte Interamericana de Derechos Humanos (Sentencia Caso López Mendoza vs. Venezuela, 2011), esto hace que la función administrativa disciplinaria en Colombia sea altamente cuestionada, sobre todo desde el punto de vista de la estructura constitucional que crea y consolida la figura de esta autoridad, como un órgano de control encargado de investigar y sancionar las conductas consideradas como faltas disciplinarias.

3 En ese sentido, conforme a lo manifestado por este Alto Tribunal los fallos adoptadas por la Procuraduría General de la Nación se traducen en actos administrativos que tienen control de legalidad, pleno e integral, por parte de la Sección Segunda del Consejo de Estado. Lo que le resta fuerza a dichas decisiones, en la medida que este Alto Tribunal puede revocar su contenido tanto de forma como de fondo, como quiera que a su juicio la autonomía, la imparcialidad y la independencia son atributos propios de la función jurisdiccional, por cuanto su estructura no es piramidal o escalonada como la de la Procuraduría General de la Nación, por lo que comparar la naturaleza de este órgano de control con el rango e investidura de un juez de la república, es asemejar el carácter de las decisiones administrativas al de las decisiones judiciales. 
Máxime cuando esta postura dista de la posición señalada por la Corte Constitucional en la Sentencia C-028 de 2006 (Sentencia C-028, 2006), a través de la que se indicó que el Bloque de Constitucionalidad, representado en el caso concreto por la aplicación del artículo 23 de la Convención Americana de Derechos Humanos ${ }^{4}$ (Steiner \& Uribe, 2014), no se opone al establecimiento de sanciones disciplinarias que impliquen la suspensión temporal o definitiva del ejercicio de un cargo público para combatir el fenómeno de la corrupción; ni tampoco a la facultad que tiene la Procuraduría General de la Nación para imponer sanciones disciplinarias temporales o permanentes. Por cuanto los instrumentos internacionales que forman parte del bloque de constitucionalidad sirven como parámetro para orientar el examen de constitucionalidad de las normas colombianas; pero en ningún caso fungen u operan como dispositivos normativos que puedan exceder su rango constitucional o tener el alcance de normas supranacionales (Sentencia C-028, 2006).

Además, el máximo órgano judicial de lo contencioso administrativo ha reiterado que la competencia del juez administrativo es plena sin deferencia especial de las decisiones proferidas por autoridades disciplinarias, por cuanto la presunción de legalidad del acto administrativo disciplinario es la misma que la de cualquier acto administrativo. Por tanto es "deber de la autoridad disciplinaria encontrar la verdad real de lo sucedido y para ello debe cumplir su obligación de efectuar una valoración ponderada y razonada de las pruebas recaudadas durante el trámite administrativo” (Ámbito Jurídico, 2019, pág. 1), pues aunque exista un procedimiento disciplinario regulado por la ley, no hay lugar a la restricción del control judicial, en la medida que la interpretación normativa y la valoración probatoria efectuada en sede disciplinaria es controlable judicialmente para garantizar el principio de la tutela judicial efectiva (Sentencia 2014-00049-01, 2018).

Aunada a la posición asumida por el Consejo de Estado, se suman posturas al respecto, como la de Roa Salguero (2010) y la de Moreno Romero (2014). Quienes indican que el precedente judicial formado por la jurisdicción de lo contencioso administrativo en la materia ha adquirido la suficiente relevancia, madurez y consistencia para permitir el estudio de legalidad de los fallos disciplinarios de forma específica, con aplicación de las garantías procesales y de las disposiciones sustantivas. Estas han sido consignadas en el texto

$4 \quad$ En este artículo se afirma que la ley puede reglamentar el ejercicio de los derechos y oportunidades para acceder a cargos de elección popular, exclusivamente por razones de edad, nacionalidad, residencia, idioma, instrucción, capacidad civil o mental, o condena, por juez competente, en proceso penal. 
constitucional para revocar, total o parcialmente, la sanción disciplinaria impuesta al servidor público, con ocasión del insuficiente análisis probatorio surtido dentro del proceso, en aras de respaldar el cumplimiento de la tutela judicial efectiva al interior de la justicia material consagrada por el Estado Social de Derecho.

Queda claro entonces que actualmente la labor del juez administrativo en el marco del control de legalidad a los actos administrativos disciplinarios, proferidos por autoridades disciplinarias como la Procuraduría General de la Nación, no reconoce límites. De tal manera que, la anulación de estas decisiones, al igual que la modificación o sustitución en todo o parte de su contenido es completamente viable (Sentencia 2018-00062-01, 2018). Lo que junto a referentes doctrinales a nivel nacional e internacional como López Higuera (2014) y Fernández y Nosquese (s.f.) justifican tanto la exclusión del concepto de cosa juzgada de los fallos administrativos disciplinarios, como la ausencia de autonomía e independencia de las autoridades administrativas disciplinarias.

\section{Conclusiones}

A partir de los acápites del presente opúsculo se puede concluir que: el interés del derecho disciplinario frente a la función pública, se centra en conductas manifiestamente irregulares que han sido desplegadas por un servidor público o un particular que ejerce función pública; pues su espectro de aplicación opera a partir del momento en que se incumple un deber funcional, materializado en una ilicitud proveniente de la vulneración del régimen de inhabilidades, incompatibilidades, deberes, prohibiciones y conflictos de intereses por acción, omisión o extralimitación en la realización de sus labores.

De esta forma, el derecho disciplinario se emplea en la actualidad como un instrumento encaminado a enderezar las conductas desplegadas por los servidores públicos en el ejercicio de sus actividades. Este le permite cumplir con las reglas de sujeción impuestas por el ordenamiento jurídico adoptado por el Estado. Lo que justifica el ejercicio de dicha potestad sancionatoria desde "la inspección jerárquica, la sanción normalizadora y su combinación en un procedimiento que le es específico: examen” (Márquez, 2010, p. 121).

En ese sentido, el derecho disciplinario enmarca una situación o comportamiento reprochable a la luz de la función pública propiciado por 
un agente o autoridad pública. Dado que genera una perturbación al deber funcional de las instituciones o procesos que tiene a cargo, ante lo que el mismo Estado hace uso de su titularidad sancionatoria y otorga la competencia a ciertos funcionarios u órganos específicos de carácter administrativo y judicial para que ejerzan la potestad disciplinaria y promuevan un control de autotutela respecto de todos los individuos que investidos con la calidad de servidor públicos, vinculados legal y reglamentariamente con el Estado; así como de particulares que en el cumplimiento de sus funciones tengan a cargo la administración de recursos públicos o el cumplimiento de una función pública en general.

Por otra parte, se tiene que el control de legalidad promovido contra los actos administrativos disciplinarios por medio del control de nulidad y restablecimiento del derecho ante la jurisdicción de lo contencioso administrativo, no constituye una transgresión de las potestades disciplinarias ejercidas por la Procuraduría General de la Nación; por cuanto la naturaleza de los fallos disciplinarios permite la revisión de los mismos por parte de esta autoridad judicial.

En este sentido, el control pleno e integral puede ser justificado de una manera moderada, en la medida que lo que se pretenda lograr con este activismo judicial es garantizar principios como la justicia material efectiva, la seguridad jurídica y la confianza legítima al interior de las decisiones judiciales. En aras de evitar la adopción de sanciones disciplinarias arbitrarias e injustas contra servidores públicos o particulares que cumplan funciones públicas (Sentencia C-328, 2015).

Por tanto, si se observa desde un punto de vista objetivo, el argumento de falta del principio del juez natural en las decisiones disciplinarias proferidas por autoridades administrativas u órganos de control, como la Procuraduría General de la Nación, carece de validez en la medida que el mismo texto constitucional le otorga y reconoce la potestad disciplinaria a estas instituciones. Con lo que se indica que la materialidad de la garantía de juzgamiento por parte de un juez o tribunal competente, independiente, imparcial y preexistente, aplicable al caso del derecho administrativo disciplinario según lo ordena el bloque de constitucionalidad y lo establece e inspira la Corte Constitucional (Sentencia C-328, 2015), se cumple en los términos de jurisdicción y competencia que se deben satisfacer como presupuestos procesales en cualquier área del derecho (Sevilla, 2015). 
De esta forma, vale la pena afirmar que el argumento en contra de la Procuraduría General de la Nación, que serviría para contrarrestar el ejercicio de su potestad administrativa disciplinaria, yace más en la ausencia de su reconocimiento como autoridad judicial para administrar justicia. Lo que sí le aminora autonomía e independencia en la medida que la eficacia de sus decisiones están vedadas por el control de legalidad promovido frente a ellas por parte de la jurisdicción contencioso administrativo, pues en lo que sí le asiste razón al Consejo de Estado, es que el contenido de la sanción disciplinaria si puede entrar a ser cuestionada de fondo para ser confirmada, modificada o revocada, por tratarse aquella de un mero acto administrativo que es susceptible de revisión por dicha jurisdicción en el marco de las causales de ilegalidad que prevé el artículo 137 del Código de Procedimiento Administrativo y de lo Contencioso Administrativo (Ley 1437, 2011, art. 137). Por tanto, en el caso de prosperar alguna de aquellas es apenas lógico que la sanción no podría mantenerse incólume y, por ende, su ajuste o anulación daría lugar a la pérdida de la validez parcial o total que ya revestía ese acto.

En este orden de ideas, al no formar parte de la estructura del poder judicial, la Procuraduría General de la Nación, aunque tenga la competencia que le ha sido conferida por la Constitución como órgano de control preexistente, autónomo, independiente e imparcial para sancionar disciplinariamente a servidores públicos o particulares que cumplan funciones públicas; su potestad, ejercicio o actividad se halla restringida por el control de legalidad efectuado a sus decisiones por parte de la jurisdicción de lo contencioso administrativo. Esto limita, a su vez, el principio del juez natural, en la medida de que sus fallos, al no quedar en firme siempre en sede administrativa; sino en sede judicial, harían tránsito por regla general a cosa juzgada formal; mas no a cosa juzgada material.

A partir de lo anterior, se plantea la necesidad actual, pertinente, útil y real de reformar constitucionalmente la estructura de la Procuraduría General de la Nación, como simple órgano de control, que desde un carácter administrativo ostentala facultad para investigary sancionar disciplinariamente a los servidores públicos, conforme a la facultad que le fue otorgada constitucionalmente para tal efecto. En aras de lograr su consolidación como una autoridad judicial, que garantice el respeto de sus decisiones sancionatorias en el marco de la autonomía e independencia que le ha sido limitada hasta el momento; en la medida que el control de legalidad a sus fallos en sede judicial le ha restado fuerza, reconocimiento y credibilidad como institución. Por tanto, la reestructuración de esta figura también beneficiaría al funcionamiento del 
sistema disciplinario, en términos de transparencia, rectitud e imparcialidad de las decisiones adoptadas por las nuevas autoridades disciplinarias. Por cuanto el nombramiento de funcionarios judiciales que tengan a cargo el ejercicio de la potestad disciplinaría haría que se prescinda de la elección de autoridades disciplinarias con injerencia política de servidores públicos. Esto ocurre actualmente en Colombia, donde la elección del Procurador General de la Nación por mandato constitucional está a cargo del Senado, para un período de cuatro años, de terna integrada por candidatos del Presidente de la República, la Corte Suprema de Justicia y el Consejo de Estado.

En suma, a manera de conclusión final, se tiene que la Procuraduría General de la Nación, al no formar parte de los órganos que en su esencia integran la administración de justicia, su calidad de juez natural en los procesos disciplinarios adelantados contra servidores públicos o particulares que cumplen funciones públicas en el orden administrativo se reconoce de manera restringida, aunque cuente con competencia otorgada por la Constitución como órgano de control preexistente, independiente e imparcial para tal efecto. Dado que en su estructura fue creada como una autoridad independiente de las demás ramas del poder público; pero con naturaleza administrativa en sus decisiones por tratarse de un órgano de control. Esto ameritará próximamente la realización de una reforma constitucional que reestructure esta institución como un órgano jurisdiccional que garantice la naturaleza judicial de sus decisiones y, por ende, evite los cuestionamientos que se hagan en torno al ejercicio de la potestad administrativa disciplinaria. No obstante, también puede avizorarse como propuesta viable para nuestro ordenamiento, la separación de la función investigadora de la función sancionatoria en materia del derecho administrativo disciplinario. De tal forma que la función de investigación quedaría en manos de las autoridades a las que constitucional y legalmente se les ha conferido o atribuido el ejercicio de la potestad disciplinaria, al tener siempre presente que el poder preferente para investigar lo tendría la Procuraduría General de la Nación, como órgano de control disciplinario superior. En tanto que la función sancionadora quedaría en manos de la jurisdicción de lo contencioso administrativo, que tiene como cabeza al Consejo de Estado, en calidad de máxima autoridad judicial de lo contencioso administrativo, con lo que se garantizaría la independencia e imparcialidad objetiva en los procesos disciplinarios, como lo proponen también algunos autores, como Fabio Humar Jaramillo (2018) y Mauricio Barón (2011) en el marco del diseño de un sistema acusatorio adecuado para el derecho administrativo disciplinario. 


\section{Referencias}

Ámbito Jurídico. (24 de Abril de 2019). La Competencia del Juez Administrativo en fallos disciplinarios, según el Consejo de Estado. Obtenido de https://www.ambitojuridico. $\mathrm{com} /$ noticias/administrativo/procesal-y-disciplinario/la-competencia-del-juezadministrativo-en-fallos

Ardila Quiroz, L. E., Oviedo Castro, J. C., \& Pineda Álvarez, Ó. (2010). Naturaleza Jurídica del Derecho Disciplinario de los Servidores Públicos en Colombia. Bogotá: Universidad Libre de Colombia.

Arráez, M., Calles, J., \& Moreno de Tovar, L. (2006). La Hermenéutica: Una actividad interpretativa. Sapiens. Revista Universitaria de Investigación, 7(2), 171-181.

Barón, M. (2011). Las garantías fundamentales frente al proceso disciplinario en Colombia. Derecho y Realidad(18), 166-188. Obtenido de https://revistas.uptc.edu. co/revistas/index.php/derecho_realidad/article/download/4895/3985

Basconelos, N. I. (2005). La Función Pública como Relación Especial del Derecho Administrativo. Madrid, España: Universidad Complutense de Madrid.

Boletín Oficial del Día. (2014). Código de Ética de la Función Pública Argentina. Buenos Aires, Argentina: El Cid Editor.

Centro Latinoamericano de Administración para el Desarrollo-CLAD. (10 de Octubre de 2013). Carta Iberoamericana de los Derechos y Deberes del ciudadano en relación con la Administración Pública. Obtenido de Carta Iberoamericana de los Derechos y Deberes del ciudadano en relación con la Administración Pública: http:// intercoonecta.aecid.es/Documentos\%20de\%20la\%20comunidad/Carta_\%20 Derechos\%20y\%20Deberes\%20Ciudadano.pdf.

Fernández, B. \& Nosquese, L. I. (s.f). El Control de Legalidad y el Principio de Revisión de los Actos Administrativos. Obtenido de https: //www.google.com.co/url?sa=t\&rc $\mathrm{t}=\mathrm{j} \& \mathrm{q}=\& \mathrm{esrc}=\mathrm{s} \&$ source $=$ web\& $\mathrm{cd}=1 \& \mathrm{cad}=\mathrm{rja} \&$ uact $=8 \& \mathrm{ved}=0 \mathrm{CBwQFjAAahUKE}$ wjtp5D82obGAhUE8I

Forero, J.R. (2016). La Moralidad Administrativa en el Ámbito del Estado Constitucional Colombiano: Realidad o Utopía. En N. E. Pardo Posada, Perspectivas Críticas del Derecho Constitucional Colombiano (págs. 13-36). Bogotá D.C.: Universidad Libre.

Gómez Pavajeau, C. A. (2012). El Derecho Disciplinario como Disciplina Jurídica Autónoma. Derecho Penal y Criminología, 33(95), 51-68.

Gómez Pavajeau, C. A., \& Sánchez Herrera, E. M. (2009). Lecciones de Derecho Disciplinario (Vol. VI). Bogotá D.C.: Instituto de Estudios del Ministerio Público.

Gómez, C. (2004). Dogmática del Derecho Disciplinario . Bogotá D.C.: Universidad Externado de Colombia.

Gómez, C. (2011). El Derecho Disciplinario en Colombia "Estado del Arte". Derecho Penal y Criminología, 32(92), 115-154.

Gordillo, A. (2012). Tratado de Derecho Administrativo (Vol. 5). Buenos Aires, Argentina: Fundación de Derecho Administrativo. Obtenido de http://www.gordillo.com/pdf_ tomo5/01/01-capitulo6.pdf

Hernández, R. (2014). Metodología de la Investigación (Sexta ed.). México D.F.: Mc Graw Hill. 
Humar, F. (22 de Febrero de 2018). Ámbito Jurídico. Obtenido de https://www. ambitojuridico.com/noticias/especiales/penal/la-aplicacion-de-los-principios-delsistema-acusatorio-en-el-proceso

Instituto de Estudios del Ministerio Público. (2007). Lecciones de Derecho Disciplinario (Vol. II). Bogotá D.C.: Instituto de Estudios del Ministerio Público.

López Pedraza, H. A., \& Yara Delgado, S. J. (2011). Responsabilidad de los Servidores Públicos en el Desarrollo de la Contratación Estatal. Bogotá D.C.: Universidad Militar Nueva Granada. Obtenido de http://repository.unimilitar.edu.co/ handle/10654/3563

López. J. L. (2014). Control Judicial de las Decisiones Disciplinarias. Bogotá D.C.: Universidad Nacional de Colombia.

Márquez, D. (2010). Función Jurídica de Control de la Administración Pública. Ciudad de México, México: Instituto de Investigaciones Jurídicas UNAM.

Moreno, I. (2014). Las Decisiones Disciplinarias de la Procuraduría General de la Nación y su Control de Legalidad en la Jurisdicción. Bogotá D.C.: Universidad Nacional de Colombia.

Ramírez-Torrado, M. L., \& Aníbal-Bendek, H. V. (2015). Sanción Administrativa en Colombia. Vniversitas(131), 107-148. doi:10.11144/Javeriana.vj131.saec

República de Colombia. (20 de Julio de 1991). Asamblea Nacional Constituyente. Constitución Política de 1991. Gaceta Constitucional N 116 (1991). Obtenido de Constitución Política de 1991: http://www.secretariasenado.gov.co/senado/ basedoc/constitucion_politica_1991.html

República de Colombia. Congreso de la República de Colombia. (05 de Febrero de 2011). Ley 734 de 2002. Por la cual se expide el Código Disciplinario Unico. Obtenido de http://www.secretariasenado.gov.co/senado/basedoc/ley_0734_2002.html

República de Colombia. Congreso de la República de Colombia. (18 de Enero de 2011). Ley 1437 de 2011. Por la cual se expide el Código de Procedimiento Administrativo y de lo Contencioso Administrativo. Obtenido de http://www.secretariasenado.gov. co/senado/basedoc/ley_1437_2011.html

República de Colombia. Congreso de la República de Colombia. (12 de Julio de 2011). Ley 1474 de 2011. Por la cual se dictan normas orientadas a fortalecer los mecanismos de prevención, investigación y sanción de actos de corrupción y la efectividad del control de la gestión pública. Obtenido de http://www.secretariasenado.gov.co/ senado/basedoc/ley_1474_2011.html

República de Colombia. Congreso de la República de Colombia. (28 de Enero de 2019). Ley 1952 de 2019. Por medio de la cual se expide el Código General Disciplinario, se derogan la Ley 734 de 2002 y algunas disposiciones de la Ley 1474 de 2011, relacionadas con el derecho disciplinario. Obtenido de http://www.secretariasenado. gov.co/senado/basedoc/ley_1952_2019.html

Roa, D.A. (2010). Construcción Dogmática del Derecho Disciplinario (Vol. I). Bogotá D.C.: Ibáñez.

Consejo de Estado. Sección Segunda (2009). Bogotá D.C. Sentencia 2005-00113-00. CP: Víctor Hernando Alvarado Ardila.

Consejo de Estado. Sección Segunda (2010). Bogotá D.C. Sentencia 2004-05678-02. CP: Víctor Hernando Alvarado Ardila.

Consejo de Estado. Sección Segunda (2011). Bogotá D.C. Sentencia 2008-00072-00. CP: Víctor Hernando Alvarado Ardila. 
Consejo de Estado. Sección Segunda (2013). Bogotá D.C. Sentencia 2011-00115-00. CP: Gustavo Eduardo Gómez Aranguren.

Consejo de Estado. Sección Segunda (2013). Bogotá D.C. Sentencia 2011-00122-00. CP: Gustavo Eduardo Gómez Aranguren.

Consejo de Estado. Sección Segunda (2013). Bogotá D.C. Sentencia 2011-00190-00. CP: Gustavo Eduardo Gómez Aranguren.

Consejo de Estado. Sala Plena de lo Contencioso Administrativo (2016). Bogotá D.C. Sentencia 2011-00316-00. CP: William Hernández Gómez (E).

Consejo de Estado. Sección Segunda (2018). Bogotá D.C. Sentencia 2013-01092-00. CP: William Hernández Gómez.

Consejo de Estado. Sección Segunda (2018). Bogotá D.C. Sentencia 2014-00049-01. CP: William Hernández Gómez.

Consejo de Estado. Sección Primera (2018). Bogotá D.C. Sentencia 2018-00062-01. CP: Hernando Sánchez Sánchez.

Corte Constitucional (1996). Bogotá D.C. Sentencia C-341 del 5 de Agosto de 1996. MP: Antonio Barrera Carbonell.

Corte Constitucional. Sala Plena (2003). Bogotá D.C. Sentencia C-252 del 25 de Marzo de 2003. MP: Jaime Córdoba Triviño.

Corte Constitucional. Sala Plena (2005). Bogotá D.C. Sentencia C-818 del 9 de Agosto de 2005. MP: Rodrigo Escobar Gil.

Corte Constitucional (2012). Bogotá D.C. Sentencia C-306 del 26 de Abril de 2012. MP: Mauricio González Cuervo.

Corte Constitucional (2014). Bogotá D.C. Sentencia C-500 del 16 de Julio de 2014. MP: Mauricio González Cuervo.

Corte Constitucional. Sala Plena (2015). Bogotá D.C. Sentencia C-328 del 27 de Mayo de 2015. MP: Luis Guillermo Guerrero Pérez.

Corte Constitucional. Sala Plena (2018). Bogotá D.C. Sentencia C-028 del 26 de Enero de 2006. MP: Humberto Antonio Sierra Porto.

Corte Interamericana de Derechos Humanos (2011). San José de Costa Rica. Sentencia Caso López Mendoza vs. Venezuela (Fondo, Reparaciones y Costas) del 1 de Septiembre de 2011. Presidente - Juez Diego García-Sayán.

Sevilla, P. H. (2015). Los presupuestos procesales para la Corte Suprema. Instituto Pacífico, 14, 236-250. Obtenido de https://www.academia.edu/17069880/LOS PRESUPUESTOS_PROCESALES_PARA_LA_CORTE_SUPREMA

Steiner, C., \& Uribe, P. (2014). Convención Americana sobre Derechos Humanos comentada (Primera ed.). Distrito Federal, México: Konrad Adenauer Stiftung. Obtenido de http://www.corteidh.or.cr/tablas/30237.pdf 